\section{Epidermal Cyst on the Sole}

Kyung Min Lee ${ }^{1}$, Jun Hyung Park ${ }^{1}$, Kyung Hee Min ${ }^{1}$, Eun Kyung Kim²

Departments of ${ }^{1}$ Plastic and Reconstructive Surgery and ${ }^{2}$ Pathology, Eulji General Hospital, Eulji University School of Medicine, Seoul, Korea

Correspondence: Kyung Hee Min

Department of Plastic and Reconstructive Surgery, Eulji General Hospital, Eulji University School of Medicine, 14 Hangeulbisuk-gil, Nowon-gu, Seoul 139-872, Korea

Tel: +82-2-970-8255, Fax: +82-2-978-4772, E-mail: mkh797@hanmail.net

No potential conflict of interest relevant to this article was reported.

Received: 26 Mar 2013 • Revised: 1 May 2013 • Accepted: 21 May 2013 pISSN: 2234-6163 • elSSN: 2234-6171

http://dx.doi.org/10.5999/aps.2013.40.4.475 • Arch Plast Surg 2013;40:475-476 Copyright (C) 2013 The Korean Society of Plastic and Reconstructive Surgeons This is an Open Access article distributed under the terms of the Creative Common Attribution Non-Commercial License (http://creativecommons.org/licenses/by-nc/3.0/) which permits unrestricted non-commercial use, distribution, and reproduction in any medium, provided the original work is properly cited.

Epidermal cysts are also called epidermal inclusion cysts, epidermoid cysts, and infundibular cysts. Clinically, they are round, firm, elevated, and movable, and they grow slowly as intradermal or subcutaneous lesions. It has been suggested that these cysts originate from the infundibular portion of the hair follicle. Therefore, they occur on hair-bearing areas primarily including the scalp, face, neck, and trunk. Epidermal cysts on the palms and soles, where there are no hair follicles, are rare $[1,2]$. The etiology of epidermal cysts on the palms and soles may be different from those caused by inflammation of the hair follicle. Traumatic implantation of epidermal elements into the dermis at the time of trauma has been suggested as a pathogenesis of epidermal cysts on the palm and sole [1-3]. Epidermal cysts on the palms and soles are easily confused with warts or calluses. This misdiagnosis may lead to improper treatment [1]. We report two cases of epidermal cysts on the sole treated by surgical extirpation.

A 16-year-old boy developed a mild tender lesion on the sole of his left foot that grew slowly for 3 months. There was no history of trauma to the sole. However, he had undergone treatment for some corns on the sole of his left foot several years earlier. As the lesion grew, walking became painful. On examination, the lesion was elevated, firm, round, movable, $2 \mathrm{~cm}$ in diameter, and overlying the second metatarsal. A mild callus had formed overlying the lesion (Fig. 1). Foot sonography showed that there was a heterogeneous hypoechoic cystic mass in the

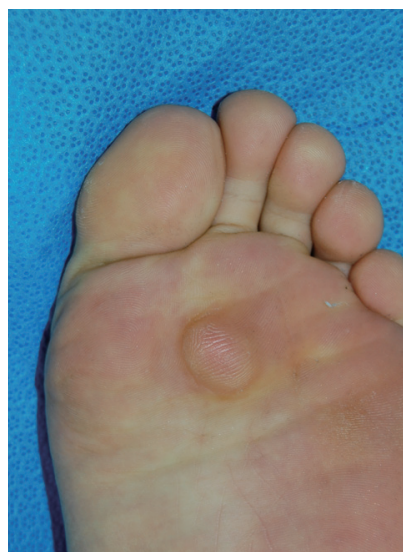

Fig. 1.

The mass was elevated, firm, round, movable, $2 \mathrm{~cm}$ in diameter, and overlying the second metatarsal.

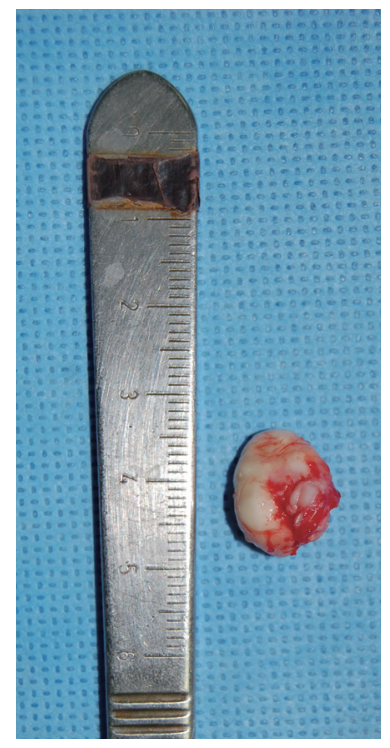

Fig. 2.

The $1.5 \mathrm{~cm}$ mass had the typical appearance of an epidermal cyst, with a white cystic wall and cheesy material.

subcutaneous layer. The lesion was extirpated and closed primarily. Macroscopically, there was the typical appearance of the epidermal cyst with a white cystic wall and cheesy material (Fig. 2). The histopathological section showed that it was an epidermal cyst (Fig. 3).

A 15-year-old girl was referred for treatment of a palpable lesion that had been on the sole of her left foot for 2 months. There was no known history of trauma to the sole. The lesion was painful on walking. Physical examination showed that there was not elevated, but was a round, movable, palpable nodule $1 \mathrm{~cm}$ in diameter, overlying the third metatarsal. A mild callus had formed overlying the lesion (Fig. 4). The foot sonography showed that there was an oval heterogeneous hypoechoic mass in the subcutaneous layer (Fig. 5). A white cystic lesion with thick, white exudate was extirpated and closed primarily. The histopathological report was an epidermal cyst.

Epidermal cysts on the sole and plantar epidermal cysts are thought to occur following traumatic implantation of epidermal cells into the dermis [1-3]. The soles receive continuous mechanical pressure during standing, walking, and running. Lemont [3] reported a histologic review of 120 keratinous cysts of the foot. The locations of all the epidermal cysts were plantar, with the greatest number on the lateral borders of the sole. Most of the patients with plantar epidermal cysts were 20 to 35 years of age. Lemont [3] suggested that this result showed that varus-functioning feet are common at young ages and the lateral borders of the feet are more susceptible to the shearing 


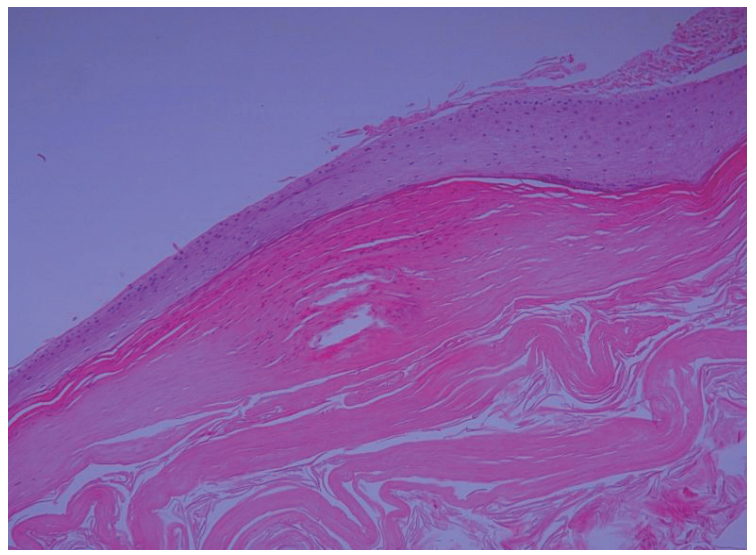

Fig. 3.

The cyst is lined by stratified squamous epithelium and contains lamellated keratins $(H \& E, \times 100)$.

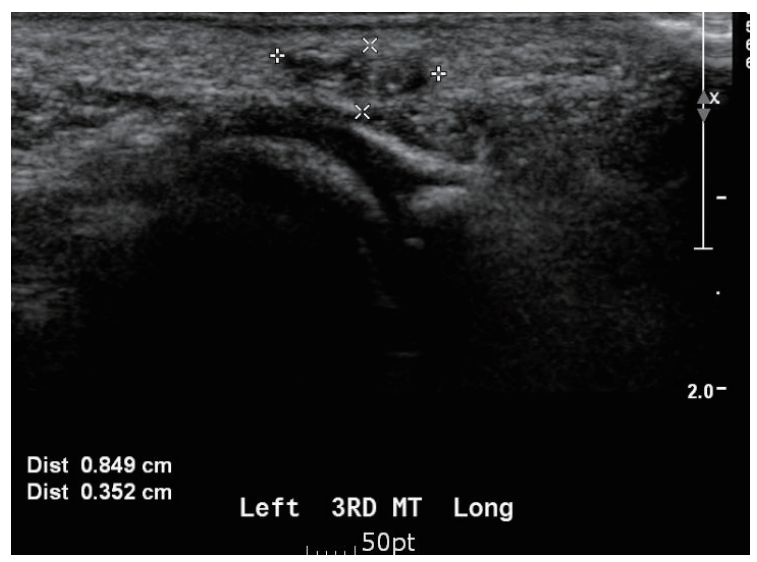

Fig. 5.

A benign superficial soft tissue tumor on the left sole. Foot sonography showed that there was an oval heterogeneous hypoechoic mass in the subcutaneous layer.

force that induces epidermal implantation. A history of plantar lesions, such as corns and related invasive treatments, could induce traumatic epidermal traumatic epidermal implnatation, as in a case of 16-year-old boy.

There are also suggestions that plantar epidermal cyst may develop from eccrine ducts due to human papillomavirus infection, not from epidermal implantation [4]. However, Shimizu et al. [2] compared the clinical and histopathologic findings of plantar epidermal cysts with those of traditional epidermal cysts and trichilemmal cysts. They reported that most cases of plantar epidermal cyst are true traumatic epidermal inclusion cysts [2].

Plantar epidermal cysts need to be differentiated from calluses, warts, neuromas, ganglion cysts, lipomas, fibromas, and other appendageal tumors [1]. Above

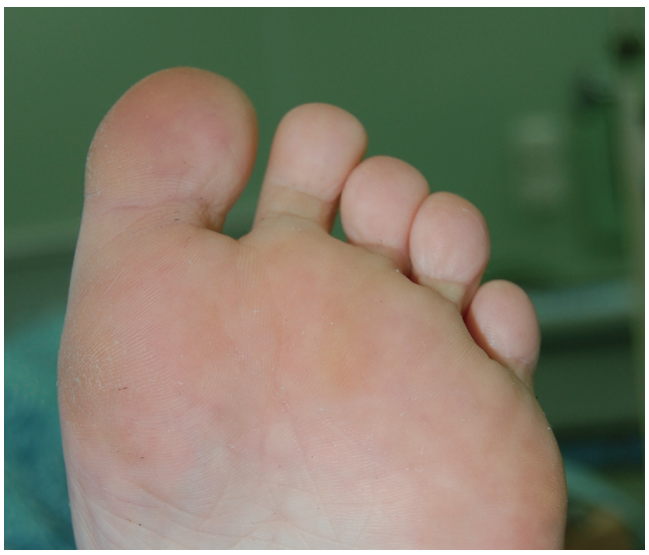

Fig. 4.

The mass was not elevated, but was a round, movable, $1 \mathrm{~cm}$ in diameter palpable nodule, overlying the third metatarsal.

all, they are frequently misdiagnosed as calluses or warts. A callus is the non-painful localized focus of hyperkeratosis, arising on the plantar area from pressure or foot deformity [5]. Plantar warts are only slightly elevated and appear as a horny plug surrounded by a ring of hyperkeratotic skin. They are frequently seen over pressure points [5]. For appropriate treatment to nodular lesions of the sole, meticulous examination or radiologic evaluation is needed.

\section{References}

1. Fisher BK, Macpherson M. Epidermoid cyst of the sole. J Am Acad Dermatol 1986;15:1127-9.

2. Shimizu Y, Sakita K, Arai E, et al. Clinicopathologic features of epidermal cysts of the sole: comparison with traditional epidermal cysts and trichilemmal cysts. J Cutan Pathol 2005;32:280-5.

3. Lemont H. Keratinous cysts of the foot: a histological review of 120 cases. J Am Podiatry Assoc 1975;65:103-6.

4. Egawa K, Honda Y, Inaba Y, et al. Detection of human papillomaviruses and eccrine ducts in palmoplantar epidermoid cysts. Br J Dermatol 1995; 132:533-42.

5. McKee PH, Brenn T, Calonje JE, et al. Pathology of the skin with clinical correlations. 3rd ed. Philadelphia: Elsevier Mosby; 2005. 